\title{
INFLUÊNCIA DAS SUPERFÍCIES GEOMÓRFICAS NA DISTRIBUIÇÃO ESPACIAL DOS ATRIBUTOS DO SOLO EM ÁREA SOB CULTIVO DE CANA-DE-AÇÚCAR ${ }^{1}$
}

\author{
Milton César Costa Campos², José Marques Júnior ${ }^{3}$, Gener Tadeu Pereira ${ }^{4}$
}

\begin{abstract}
INFLUENCE OF GEOMORPHIC SURFACES ON THE

SPATIAL DISTRIBUTION OF SOIL ATTRIBUTES IN A SUGARCANE CULTIVATION AREA

Variations in soil attributes occur based on relief forms and parent material. The objective of this research was to study the influences of geomorphic surfaces on the spatial distribution of soil attributes in a sugarcane cultivation area. First, 530,67 hectares were mapped by using a Global Positioning System. Then, a Digital Elevation Model was developed and geomorphic surfaces were identified and delimited, according to topographic and stratigraphic criteria based on detailed field investigations. Soil samples were collected every $7 \mathrm{ha}$, at $0.0-0.25 \mathrm{~m}$ and $0.80-$ $1.00 \mathrm{~m}$ depths, totalizing 134 samples. Texture, $\mathrm{Ca}, \mathrm{K}, \mathrm{Mg}, \mathrm{SB}$, $\mathrm{CEC}, \mathrm{V} \%, \mathrm{pH}$, and OMS analyses were carried out as well as descriptive statistics and geostatistics analysis. It was concluded that the geostatistic techniques and digital elevation model helped to notice that soil attributes presented limits close to the geomorphic surfaces ones.
\end{abstract}

KEY-WORDS: Soil attributes; geomorphic surface; soillandscape relationship; landscape form.

\section{INTRODUÇÃO}

Considerando-se que as formas de relevo exercem papel decisivo no tempo de exposição dos materiais de origem dos solos e na intensidade e direção do fluxo da água no perfil solo, regulando as variações nos processos pedogenéticos, o estudo e a observação das diferentes formas da paisagem, tais formas tornam-se premissa básica na execução de levantamentos pedológicos (Bui 2004).

Assim sendo, o uso de modelos de paisagem, como técnica auxiliar em levantamento de solo,

\section{RESUMO}

As variações dos atributos do solo ocorrem em função das formas do relevo e do material de origem. Sendo assim, o objetivo deste trabalho foi estudar as influências das superfícies geomórficas na distribuição espacial dos atributos do solo, em área cultivada com cana-de-açúcar. Foi realizado o mapeamento de uma área de 530,67 hectares, utilizando-se equipamento de Sistema de Posicionamento Global. Em seguida, foi elaborado o Modelo de Elevação Digital e identificadas e delimitadas as superfícies geomórficas, conforme critérios topográficos e estratigráficos, com base em intensas investigações de campo. Foram coletadas amostras de solo a cada 7 ha, nas profundidades de 0,0-0,25 $\mathrm{m}$ e $0,80-1,00 \mathrm{~m}$, totalizando 134 amostras. Foram realizadas análises granulométrica e de $\mathrm{Ca}, \mathrm{K}$, $\mathrm{Mg}, \mathrm{SB}, \mathrm{CTC}, \mathrm{V} \%$, MO e pH, bem como estatísticas descritivas e análise geoestatística. Concluiu-se que o auxílio de técnicas de geoestatística e modelo de elevação digital possibilitaram observar que os atributos do solo apresentaram limites próximos aos das superfícies geomórficas.

PALAVRAS-CHAVE: Atributos do solo; superfície geomórfica; relação solo-paisagem; forma da paisagem.

constitui uma evolução no entendimento das relações solo-geomorfologia, tornando-se importante ferramenta no auxílio ao mapeamento de áreas com solos mais homogêneos, de maneira que vários modelos de paisagem se propõem a estudar e entender as relações entre as condições do solo e o relevo. Dentre estes modelos, destaca-se aquele proposto por Ruhe (1956) e Daniels et al. (1971), que estabelece a definição de superfície geomórfica, como sendo uma porção de terra que é especificamente definida no espaço e no tempo. Além disso, Vidal-Torrado \& Lepsch (1999) afirmam que as superfícies geomórficas relacionam-

1. Trabalho recebido em set./2008 e aceito para publicação em jun./2010 (n registro: PAT 4786/ DOI: 10.5216/pat.v40i2.4786).

2. Universidade Federal do Amazonas, Instituto de Educação, Agricultura e Ambiente, Colegiado de Agronomia, Humaitá, AM, Brasil. E-mail: mcesarsolos@gmail.com.

3. Universidade Estadual Paulista, Faculdade de Ciências Agrárias e Veterinárias, Departamento de Solos e Adubos, Jaboticabal, SP, Brasil.E-mail: marques@fcav.unesp.br.

4. Universidade Estadual Paulista, Faculdade de Ciências Agrárias e Veterinárias, Departamento de Ciências Exatas, Jaboticabal, SP, Brasil. E-mail: genertp@fcav.unesp.br. 
se, também, com o grau de intemperização dos solos, de maneira que haja uma relação cronológica entre os solos e as mesmas. Desta forma, as superfícies geomorficamente mais estáveis apresentariam condições para um maior desenvolvimento e estabilidade dos solos e superfícies menos estáveis possuiriam solos menos desenvolvidos e mais variados.

De acordo com Teramoto et al. (2001) e Cunha et al. (2005), a variação dos tipos de solos, assim como a estabilidade das superfícies geomórficas, está estreitamente ligada ao tempo e ao relevo. Entretanto, para se entender a relação dos modelos de paisagem e suas influências na variabilidade dos atributos do solo, com vistas à sua aplicação em levantamentos pedológicos, é muito útil o uso de técnicas geoestatísticas e a construção de Modelos de Elevação Digital (MED) (Park \& Burt 2002). De acordo com Mcbratney et al. (2003), a associação entre essas técnicas é fundamental nos estudos das relações solo-paisagem.

A abordagem tridimensional das paisagens, com os Modelos de Elevação Digitais, tem subsidiado a interpretação das relações entre a evolução pedogenética e a evolução do relevo, assim como o uso de técnicas geoestatísticas têm se apresentado como instrumento eficiente para avaliar e entender as causas da variabilidade espacial dos atributos do solo nas paisagens, principalmente em áreas onde os levantamentos de solos sejam menos detalhados, ou haja grande homogeneidade do grupamento de solos (Berg \& Oliveira 2000). Mcbratney et al. (1991) destacam que as informações topográficas melhoram a representação espacial dos atributos do solo, principalmente quando mapeados por meio de técnicas geoestatísticas.

Assim, o objetivo deste trabalho foi estudar as influências das superfícies geomórficas na distribuição espacial dos atributos do solo, em área sob cultivo de cana-de-açúcar, visando a aprofundar a compreensão sobre a gênese dos solos da região e subsidiar a extrapolação de informações para o reconhecimento de áreas vizinhas.

\section{MATERIAL E MÉTODOS}

A área de estudo está localizada ao noroeste do Estado de São Paulo, no município de Pereira Barreto $\left(20^{\circ} 35^{\prime} 10^{\prime \prime} \mathrm{S}, 51^{\circ} 11^{\prime} 02^{\prime \prime} \mathrm{W}\right.$ e altitude média de $360 \mathrm{~m}$ ). O clima da região, segundo a classificação de Köeppen, é do tipo tropical chuvoso de bosque, com chuvas de verão e estiagem no inverno (Aw), temperaturas variando entre $26,8^{\circ} \mathrm{C}$ e $21,2^{\circ} \mathrm{C}$, precipitação média anual de $1.128 \mathrm{~mm}$ e chuvas concentradas no período de novembro a fevereiro. A vegetação original caracteriza-se como floresta tropical subcaducifolia, estando a área, atualmente, sob cultivo de cana-de-açúcar.

O relevo é, predominantemente, suave ondulado, com declividades variando de $3 \%$ a $5 \%$. Nesta área, predominam os latossolos, distribuídos ao longo das vertentes (IPT 1981a). Nas posições mais elevadas e planas de colinas, encontram-se os Latossolos Vermelhos textura média, cujo material de origem derivou-se, principalmente, de arenitos da Formação Santo Anastácio, os quais transicionam, encosta abaixo, para Latossolos Vermelhos eutroférricos textura argilosa, originados, principalmente, dos produtos da alteração dos basaltos Formação Serra Geral (IPT 1981b).

Foi realizado o mapeamento de uma área de 530 hectares, utilizando-se equipamento de Sistema de Posicionamento Global (GPS). Elaborou-se o Modelo de Elevação Digital (MED), com auxílio do programa Suffer 8.0 (Golden Software Inc. 1999), o que, juntamente com os trabalhos de campo, auxiliou na identificação e delimitação das superfícies geomórficas, conforme critérios preconizados por Ruhe (1969) e Daniels et al. (1971).

Foram abertas trincheiras nas superfícies geomórficas mapeadas e a identificação dos horizontes, descrição morfológica e coleta de amostras dos horizontes dos solos foram realizadas conforme Santos et al. (2005). Os solos foram classificados segundo critérios estabelecidos pelo SiBCS (Embrapa 2006).

Coletaram-se 134 amostras de solo nas superfícies geomórficas, sendo 67 na profundidade $0,0-0,25 \mathrm{~m}$ e 67 na profundidade $0,80-1,00 \mathrm{~m}$. O critério para escolha destas duas profundidades baseou-se no fato de que, na primeira profundidade, há influência do manejo sobre os atributos e que a segunda profundidade é menos influenciada pelo manejo e está mais próxima dos horizontes diagnósticos. A quantidade de amostras de solo coletadas por superfície foi distribuída da seguinte maneira: 29 amostras de solo na superfície geomórfica I, 22 amostras na superfície geomórfica II e 16 amostras na superfície geomórfica III.

Realizou-se análise granulométrica, conforme método da pipeta, utilizando-se solução de $\mathrm{NaOH} 0,1 \mathrm{~N}$, como dispersante químico, e agitação mecânica em 
aparato de baixa rotação, por 16 horas, seguindo metodologia proposta pela Embrapa (1997). A fração argila foi separada por sedimentação gravitacional e as frações areia fina e grossa e silte calculadas por diferença.

Cálcio, magnésio e potássio trocáveis foram extraídos utilizando-se o método da resina trocadora de íons (Raij et al. 1987) e a matéria orgânica extraída segundo método proposto pela Embrapa (1997). Com base nos resultados das análises químicas, foram calculadas as somas de bases (SB), capacidade de troca catiônica (CTC) e saturação por bases (V\%). Foi determinado, ainda, o pH em KCl, utilizando-se a relação 1:2,5 de solo (Embrapa 1997).

Os dados das amostras coletadas nas áreas das superfícies geomórficas foram submetidos a análise de estatística descritiva, calculando-se a média, mediana, desvio padrão, variância, coeficiente de variação, coeficiente de assimetria e coeficiente de curtose. A hipótese de normalidade dos dados foi testada pelo teste de Kolmogorov-Smirnov, por meio do programa computacional SAS (Schlotzhaver \& Littell 1997).

Por meio de análise geoestatística, foram confeccionados semivariogramas, os quais foram ajustados, utilizando-se o programa GS + (Robertson 1998). Posteriormente, tais modelos foram usados no desenvolvimento de mapas de isolinhas (krigagem), sendo que, para a elaboração dos mapas de distribuição espacial das variáveis, utilizou-se o programa Surfer (Golden Software Inc. 1999).

\section{RESULTADOS E DISCUSSÃO}

\section{Descrição geral das superficies geomórficas}

Baseando-se nos conceitos de Ruhe (1956) e Daniels et al. (1971), foram localizadas e mapeadas três superfícies geomórficas (I, II e III). As superfícies geomórficas I e III são consideradas a mais velha e a mais nova, respectivamente (Figura 1).

A primeira superfície é formada por uma pequena área plana no topo, sendo a de maior altitude $(385 \mathrm{~m})$, e apresenta caráter deposicional, assemelhando-se às superfícies descritas por Marques Júnior \& Lepsch (2000), os quais afirmam que as superfícies geomórficas mais velhas são mais estáveis e, normalmente, encontradas nos topos das paisagens. A segunda superfície geomórfica estendese na forma de um plano inclinado, a partir das bordas da primeira superfície, em função da suave

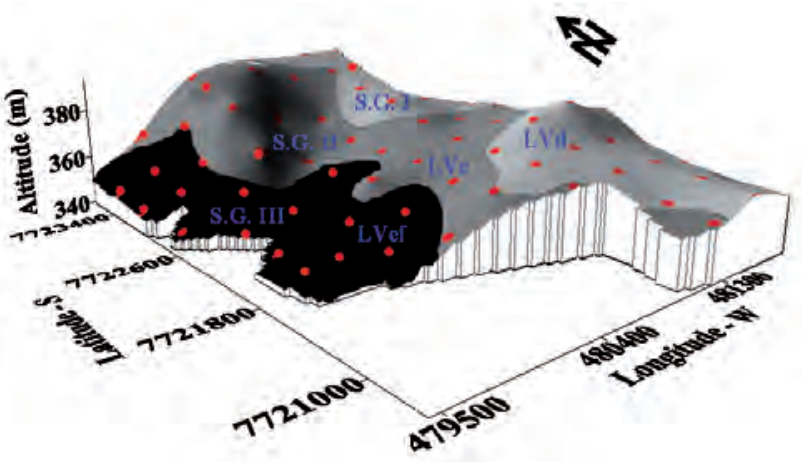

Figura 1. Modelo de Elevação Digital de uma área de 530 ha, com superfícies geomórficas (S.G.I, S.G.II, S.G.III) mapeadas, classes de solos (LVd = Latossolo Vermelho distrófico típico; $\mathrm{LVe}=$ Latossolo Vermelho eutrófico típico; e LVef = Latossolo Vermelho eutroférrico chernozêmico) e locais de amostragem (•) (Pereira Barreto, SP, 2006).

inclinação, provavelmente originada a partir de processos erosionais pretéritos. A superfície geomórfica III inicia-se na borda da superfície geomórfica II, caracterizando-se por uma declividade mais acentuada que a das anteriores, com predominância de relevo suave ondulado, estendendo-se até o fundo do vale e apresentando caráter erosional residual (Figura 1).

Quanto aos solos que ocorrem nas superfícies geomórficas, observou-se o seguinte comportamento: na superfície geomórfica I, ocorre o Latossolo Vermelho distrófico típico, desenvolvido a partir de arenitos da Formação Santo Anastácio, Grupo Bauru; a superfície geomórfica II apresenta um Latossolo Vermelho eutrófico típico, transição entre os arenitos da Formação Santo Anastácio e os basaltos da Formação Serra Geral; e, na superfície geomórfica III, há predominância de Latossolo Vermelho eutrófico chernossólico, desenvolvido a partir dos produtos da alteração dos basaltos da Formação Serra Geral (Figura 1).

Na Figura 2, observa-se a simulação do caminhamento e fluxo da água no terreno. De acordo com Bockheim et al. (2005), o relevo tem grande influência na drenagem e movimento anisotrópico da água (vertical e horizontal), provocando alterações nos atributos do solo e favorecendo a identificação de superfícies geomórficas ou superfícies pedométricas, que são genética e evolutivamente interdependentes. Gobin et al. (2001) afirmam que o movimento da água nas paisagens é o principal responsável pelo processo de desenvolvimento do solo. Por isso, compreender as formas do relevo auxilia nas inferências e predições sobre os atributos do solo, em diferentes segmentos de vertentes. 


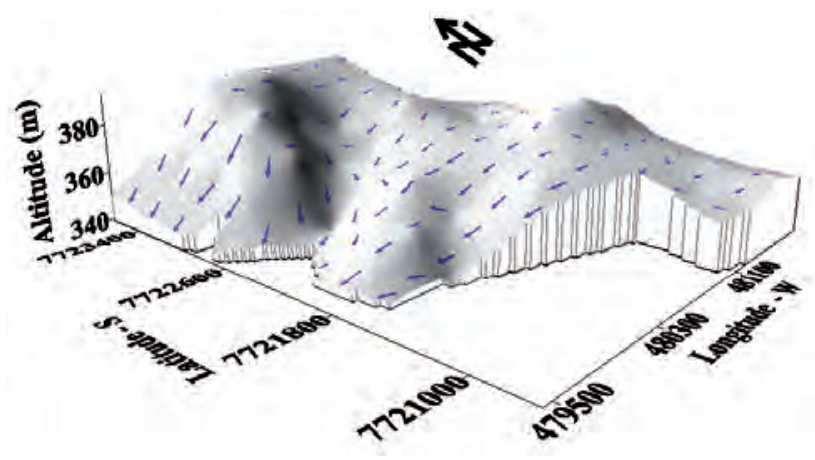

Figura 2. Modelo de Elevação Digital de uma área de 530 ha, com os vetores que simulam o caminhamento superficial da água (setas) e intensidade do fluxo de água (tamanho da seta) (Pereira Barreto, SP, 2006).

O Modelo de Elevação Digital da área estudada permite ter uma visão geral de sua fisiografia (Figura 2). De acordo com Hammer et al. (1995), quando esses modelos estão associados a mapas de variabilidade, podem figurar como importantes ferramentas para visualização e entendimento das relações de causa e efeito da distribuição espacial dos atributos do solo. Para Park \& Burt (2002), com o uso desses modelos, é possível estabelecer relações das influências da topografia, hidrologia, classes de declividade do terreno e quantidade e tipo de vegetação sobre as classes de solos e, com isso, aperfeiçoar essas informações em levantamentos de solos, estabelecendo limites mais exatos entre as classes.

\section{Análise da estatística descritiva dos atributos do solo}

Na Tabela 1, são apresentados os resultados referentes à análise descritiva para areia fina, areia grossa, silte e argila, nas duas profundidades estudadas. Observa-se que os valores da média e da mediana estão próximos para areia fina, na profundidade $0,0-0,25 \mathrm{~m}$, e areia grossa, areia fina e argila, na profundidade $0,80-1,00 \mathrm{~m}$. Os coeficientes de assimetria e curtose estão próximos de zero, para as mesmas variáveis acima citadas, o que caracteriza distribuição simétrica. Os resultados referentes ao teste Kolmogorov-Smirnov indicaram normalidade para areia fina, na profundidade $0,0-0,25 \mathrm{~m}$, e areia grossa, areia fina e argila, na profundidade $0,80-1,00 \mathrm{~m}$, similarmente ao observado por Carvalho et al. (2003).

Pelos limites de coeficiente de variação (CV) propostos por Warrick \& Nielsen (1980), para a classificação de variáveis do solo $\mathrm{CV}<12 \% ; 12 \%<$
Tabela 1. Estatística descritiva para as variáveis areia fina, areia grossa, argila e silte $\left(\mathrm{g} \mathrm{kg}^{-1}\right)$, das amostras coletadas nos pontos de cruzamento da malha (Pereira Barreto, SP, 2006).

\begin{tabular}{|c|c|c|c|c|}
\hline \multirow{4}{*}{$\begin{array}{l}\text { Estatística } \\
\text { descritiva }\end{array}$} & \multicolumn{4}{|c|}{ Atributos granulométricos } \\
\hline & Areia fina & Areia grossa & Silte & Argila \\
\hline & \multicolumn{4}{|c|}{$\mathrm{g} \mathrm{kg}^{-1}$} \\
\hline & \multicolumn{4}{|c|}{$0,0-0,25 \mathrm{~m}$} \\
\hline Média & 161,1 & 511,3 & 104,3 & 223,4 \\
\hline Mediana & 160,0 & 560,0 & 90,0 & 200,0 \\
\hline $\mathrm{DP}^{1}$ & 56,8 & 118,7 & 58,8 & 100,2 \\
\hline Variância & 3227 & 14090 & 3467 & 10060 \\
\hline $\operatorname{CV}(\%)^{2}$ & 35,1 & 23,2 & 56,4 & 44,8 \\
\hline Assimetria & 0,2 & $-1,1$ & 1,8 & 1,0 \\
\hline Curtose & $-0,8$ & 0,7 & 4,1 & 0,2 \\
\hline \multirow[t]{2}{*}{$\mathrm{d}^{3}$} & 0,16 & $0,16^{\mathrm{ns}}$ & $0,16^{\mathrm{ns}}$ & $0,15^{\text {ns }}$ \\
\hline & \multicolumn{4}{|c|}{$0,80-1,00 \mathrm{~m}$} \\
\hline Média & 506,6 & 133,3 & 111,0 & 306,1 \\
\hline Mediana & 510,0 & 130,0 & 100,0 & 304,0 \\
\hline $\mathrm{DP}^{1}$ & 128,3 & 47,8 & 52,9 & 117,8 \\
\hline Variância & 16460 & 2286 & 2800 & 13870 \\
\hline $\operatorname{CV}(\%)^{2}$ & 28,5 & 35,8 & 47,6 & 38,4 \\
\hline Assimetria & $-1,0$ & 0,2 & 2,0 & 0,9 \\
\hline Curtose & $-0,2$ & $-0,9$ & 6,2 & $-0,1$ \\
\hline $\mathrm{d}^{3}$ & 0,26 & 0,11 & $0,19^{\text {ns }}$ & 0,19 \\
\hline
\end{tabular}

${ }^{1} \mathrm{DP}=$ desvio padrão; ${ }^{2} \mathrm{CV}=$ coeficiente de variação $;{ }^{3} \mathrm{~d}=$ teste de normalidade; ${ }^{\mathrm{ns}}$ não significativo, pelo teste de Kolmogorov-Smirnov.

$\mathrm{CV}>60 \%$; e CV $>60 \%$, para variabilidade baixa, moderada e alta, respectivamente, as variáveis areia grossa, na profundidade $0,0-0,25 \mathrm{~m}$, e areia fina, na profundidade $0,80-1,00 \mathrm{~m}$, apresentaram $\mathrm{CV}$ moderado $(23,2 \%, 23,3 \%$ e $28,2 \%$, respectivamente) e, para as demais variáveis, o CV foi considerado alto (Tabela 1), concordando com os resultados encontrados por Souza et al. (2004).

O resultados dos atributos químicos são apresentado na Tabela 2 . Nota-se que os valores da média e da mediana, para as variáveis $\mathrm{pH}, \mathrm{SB}, \mathrm{V}$ e $\mathrm{MO}$, na profundidade $0,0-0,25 \mathrm{~m}$, e o $\mathrm{pH}, \mathrm{MO}$ e $\mathrm{V}$, na profundidade $0,80-1,00 \mathrm{~m}$, estão próximos, indicando distribuições simétricas. Para as demais variáveis, ocorreram valores com certo distanciamento entre a média e a mediana, o que pode ser um indicativo de distribuição de dados assimétricos, em que as medidas de tendência central são dominadas por valores atípicos, concordando com os resultados econtrados por Mello et al. (2006).

Seguindo a classificação do CV proposta por Wilding \& Drees (1983), observou-se que os valores do $\mathrm{pH}$, nas duas profundidades estudadas, apresentaram baixa variabilidade, ou seja, $\mathrm{CV}<15 \%$. Os teores de $\mathrm{MO}$ e V (\%), nas duas profundidades, e CTC, na profundidade 0,0-0,25 m, apresentaram 
Tabela 2. Estatística descritiva para as variáveis $\mathrm{pH}$, soma de bases (SB), capacidade de troca catiônica (CTC), saturação de bases $(\mathrm{V})$ e matéria orgânica (MO), nas profundidades 0,00-0,25 m e 0,80-1,00 m, em área sob cultivo de cana-de-açúcar (Pereira Barreto, SP, 2006).

\begin{tabular}{|c|c|c|c|c|c|}
\hline $\begin{array}{l}\text { Estatística } \\
\text { descritiva }\end{array}$ & $\mathrm{pH}$ & SB & $\mathrm{CTC}$ & $\mathrm{V}$ & $\mathrm{MO}$ \\
\hline & & \multicolumn{2}{|c|}{$\mathrm{mmol}_{\mathrm{c}} \mathrm{dm}^{-3}$} & $\%$ & $\mathrm{~g} \mathrm{~kg}^{-1}$ \\
\hline & \multicolumn{5}{|c|}{$0,0-0,25 \mathrm{~m}$} \\
\hline Média & 5,05 & 30,46 & 52,00 & 52,57 & 16,95 \\
\hline Mediana & 5,10 & 29,36 & 47,90 & 53,05 & 16,00 \\
\hline $\mathrm{DP}^{1}$ & 0,26 & 19,14 & 15,40 & 10,95 & 3,55 \\
\hline Variância & 0,06 & 366,56 & 237,00 & 119,91 & 20,70 \\
\hline $\operatorname{CV}(\%)^{2}$ & 5,14 & 62,83 & 29,56 & 20,82 & 20,94 \\
\hline Assimetria & $-0,25$ & 2,15 & 0,69 & 0,12 & 1,29 \\
\hline Curtose & $-0,07$ & 6,04 & $-0,73$ & 0,30 & 2,76 \\
\hline $\mathrm{d}^{3}$ & 0,14 & $0,17^{\mathrm{ns}}$ & $0,11^{\mathrm{ns}}$ & 0,08 & $0,18^{\mathrm{ns}}$ \\
\hline \multicolumn{6}{|c|}{$0,80-1,00 \mathrm{~m}$} \\
\hline Média & 5,11 & 25,53 & 45,45 & 51,71 & 8,75 \\
\hline Mediana & 5,10 & 17,50 & 37,70 & 49,37 & 8,00 \\
\hline $\mathrm{DP}^{1}$ & 0,15 & 18,46 & 19,55 & 14,47 & 2,27 \\
\hline Variância & 0,154 & 340,94 & 382,3 & 209,41 & 5,16 \\
\hline $\operatorname{CV}(\%)^{2}$ & 7,67 & 72,30 & 43,02 & 27,98 & 25,97 \\
\hline Assimetria & $-0,34$ & 1,99 & 2,06 & 0,10 & 1,18 \\
\hline Curtose & $-0,23$ & 5,09 & 5,89 & 0,66 & 1,30 \\
\hline $\mathrm{d}^{3}$ & 0,08 & $0,22^{\text {ns }}$ & $0,20^{\text {ns }}$ & 0,07 & $0,18^{\mathrm{ns}}$ \\
\hline
\end{tabular}

${ }^{1} \mathrm{DP}=$ desvio padrão $;{ }^{2} \mathrm{CV}=$ coeficiente de variação; ${ }^{3} \mathrm{~d}=$ teste de normalidade; ${ }^{\text {ns }}$ não significativo, pelo teste de Kolmogorov-Smirnov.

moderada variabilidade, isto é, $15 \%<\mathrm{CV}<35 \%$. As demais variáveis apresentaram alta variabilidade, com valores de coeficientes de variação $\mathrm{CV}>35 \%$.

\section{Análise geoestatística e superficies geomórficas}

Pelos resultados da análise geoestatística (Tabela 3), evidenciou-se que todas as variáveis analisadas apresentaram dependência espacial, haja vista que nenhum dos atributos granulométricos apresentou efeito pepita puro, o que determinaria uma distribuição aleatória dos dados (Vieira 2000). As variáveis areia fina, areia grossa, silte e argila apresentaram semivariogramas que ajustaram-se muito bem ao modelo esférico, e estes resultados foram semelhantes àqueles encontrados por Eguchi et al. (2003), estudando a variabilidade espacial de atributos texturais em solo aluvial da região de Lavras (MG).

Os parâmetros do semivariograma dos atributos químicos estudados são apresentados na Tabela 4. Todos os atributos químicos analisados apresentaram dependência espacial nas duas profundidades, sendo que o modelo esférico ajustou-se bem a todas as variáveis. De acordo com Mcbratney \& Webster (1986),
Tabela 3. Modelos e parâmetros estimados dos semivariogramas experimentais, para as variáveis areia fina, areia grossa, argila e silte $\left(\mathrm{g} \mathrm{kg}^{-1}\right)$, das amostras coletadas nos pontos de cruzamento da malha (Pereira Barreto, SP, 2006).

\begin{tabular}{|c|c|c|c|c|}
\hline \multirow{4}{*}{ Parâmetro } & \multicolumn{4}{|c|}{ Atributos granulométricos } \\
\hline & Areia fina & Areia grossa & Silte & Argila \\
\hline & \multicolumn{4}{|c|}{$\mathrm{g} \mathrm{kg}^{-1}$} \\
\hline & \multicolumn{4}{|c|}{$0,0-0,25 \mathrm{~m}$} \\
\hline Modelo & Esférico & Esférico & Esférico & Esférico \\
\hline Efeito pepita $\left(\mathrm{C}_{0}\right)$ & 40,0 & 1690 & 236 & 10,0 \\
\hline Patamar $\left(\mathrm{C}_{0}+\mathrm{C}_{1}\right)$ & 4912 & 15760 & 3103 & 16980 \\
\hline Alcance (a) & 2721 & 2424 & 2705 & 2968 \\
\hline $\mathrm{R}^{2}(\%)^{1}$ & 0,96 & 0,97 & 0,98 & 0,96 \\
\hline \multirow[t]{2}{*}{$\mathrm{SQR}^{2}$} & 837286 & 0,000047 & 142067 & 0,000001 \\
\hline & \multicolumn{4}{|c|}{$0,80-1,00 \mathrm{~m}$} \\
\hline Modelo & Esférico & Esférico & Esférico & Esférico \\
\hline Efeito pepita $\left(\mathrm{C}_{0}\right)$ & 250 & 60,0 & 400 & 10,0 \\
\hline $\operatorname{Patamar}\left(\mathrm{C}_{0}+\mathrm{C}_{1}\right)$ & 21870 & 3428 & 5693 & 19810 \\
\hline Alcance (a) & 2134 & 2857 & 2168 & 2410 \\
\hline $\mathrm{R}^{2}(\%)^{1}$ & 0,97 & 0,98 & 0,94 & 0,98 \\
\hline $\mathrm{SQR}^{2}$ & 0,000007 & 201975 & 661184 & 0,000005 \\
\hline
\end{tabular}

${ }^{1}{ }^{2}=$ coeficiente de determinação; ${ }^{2} \mathrm{SQR}=$ soma dos quadrados dos resíduos.

Tabela 4. Modelos e parâmetros estimados dos semivariogramas experimentais, para as variáveis $\mathrm{pH}$, soma de bases (SB), capacidade de troca catiônica (CTC), saturação de bases (V) e matéria orgânica (MO), das amostras coletadas nos pontos de cruzamento da malha (Pereira Barreto, SP, 2006).

\begin{tabular}{|c|c|c|c|c|c|}
\hline Parâmetro & $\mathrm{pH}$ & SB & CTC & $\mathrm{V}$ & $\mathrm{MO}$ \\
\hline & \multicolumn{3}{|c|}{$\mathrm{mmol}_{\mathrm{c}} \mathrm{dm}^{-3}$} & $\%$ & $\mathrm{~g} \mathrm{~kg}^{-1}$ \\
\hline & \multicolumn{5}{|c|}{$0,0-0,25 \mathrm{~m}$} \\
\hline Modelo & Esférico & Esférico & Esférico & Esférico & Esférico \\
\hline Efeito pepita $\left(\mathrm{C}_{0}\right)$ & 0,01 & 53,00 & 28,00 & 14,90 & 5,35 \\
\hline Patamar $\left(\mathrm{C}_{0}+\mathrm{C}_{1}\right)$ & 0,06 & 392,90 & 706,90 & 109,30 & 13,96 \\
\hline Alcance (a) & 2013 & 2128 & 2787 & 2389 & 1885 \\
\hline $\mathrm{RD}=\left[\mathrm{C}_{0} /\left(\mathrm{C}_{0}+\mathrm{C}_{1}\right)\right] \times 100^{2}$ & 16,67 & 13,49 & 3,96 & 13,63 & 38,32 \\
\hline $\mathrm{R}^{2}(\%)^{1}$ & 0,98 & 0,99 & 0,98 & 0,98 & 0,97 \\
\hline \multirow[t]{2}{*}{$\mathrm{SQR}^{2}$} & 0,01 & 911 & 8064 & 130 & 2,23 \\
\hline & \multicolumn{5}{|c|}{$0,80-1,00 \mathrm{~m}$} \\
\hline Modelo & Esférico & Esférico & Esférico & Esférico & Esférico \\
\hline Efeito pepita $\left(\mathrm{C}_{0}\right)$ & 0,02 & 3,20 & 107 & 43,90 & 1,65 \\
\hline Patamar $\left(\mathrm{C}_{0}+\mathrm{C}_{1}\right)$ & 0,16 & 285,70 & 525 & 214 & 4,55 \\
\hline Alcance (a) & 1760 & 3055 & 2572 & 1637 & 2408 \\
\hline $\mathrm{RD}=\left[\mathrm{C}_{0} /\left(\mathrm{C}_{0}+\mathrm{C}_{1}\right)\right] \times 100^{2}$ & 2,50 & 11,12 & 20,38 & 20,51 & 36,26 \\
\hline $\mathrm{R}^{2}(\%)^{1}$ & 0,81 & 0,97 & 0,97 & 0,95 & 0,87 \\
\hline $\mathrm{SQR}^{2}$ & 0,01 & 1306 & 5605 & 1140 & 1,13 \\
\hline
\end{tabular}

${ }^{1} \mathrm{RD}=$ razão de dependência espacial; ${ }^{2} \mathrm{R}^{2}=$ coeficiente de determinação $;{ }^{3} \mathrm{SQR}=$ soma dos quadrados dos resíduos.

o modelo matemático esférico é o que mais se ajusta às propriedades do solo.

A respeito da razão de dependência $(\mathrm{RD}), \mathrm{ob}-$ serva-se (Tabela 4) que, na profundidade $0,0-0,25 \mathrm{~m}$, apenas a MO apresentou moderada dependência espacial (26-75\%), ao passo que as demais variáveis apresentaram alta dependência espacial $(<26 \%)$. Já na profundidade $0,80-1,00 \mathrm{~m}$, apenas a $\mathrm{MO}$ apresentou moderada dependência espacial (26-75\%), enquanto as demais apresentaram alta dependência 
espacial $(<26 \%)$, concordando com Carvalho et al. (2002).

Os mapas de isolinhas das frações areia fina e areia grossa apresentaram comportamento similar, nas duas profundidades, exibindo distribuição espacial coincidente com as superfícies geomórficas estudadas (Figura 3), sendo que os maiores conteúdos destas frações encontram-se nas partes mais elevadas do terreno, influenciados, principalmente, pelo material de origem em arenitos da Formação Santo Anastácio. Os maiores conteúdos de argila e silte concentraram-se em áreas de menores cotas (Figura 3), em função, principalmente, de sua origem basáltica. Resultados similares foram encontrados por Cunha et al. (2005). Segundo Yoo et al. (2006), a variação da textura é controlada por fatores topográficos e pela ação da água que governa a erosão e deposição dos solos nas paisagens.

De forma geral, os mapas de krigagem das frações granulométricas do solo apresentaram variação espacial semelhante à das superfícies geomórficas estudadas. A superfície geomórfica mais velha e mais estável apresentou os maiores valores para areia fina e grossa, enquanto as frações mais finas (argila e silte) mostraram maiores valores nas superfícies mais jovens (Figura 3), fato que pode estar ligado,
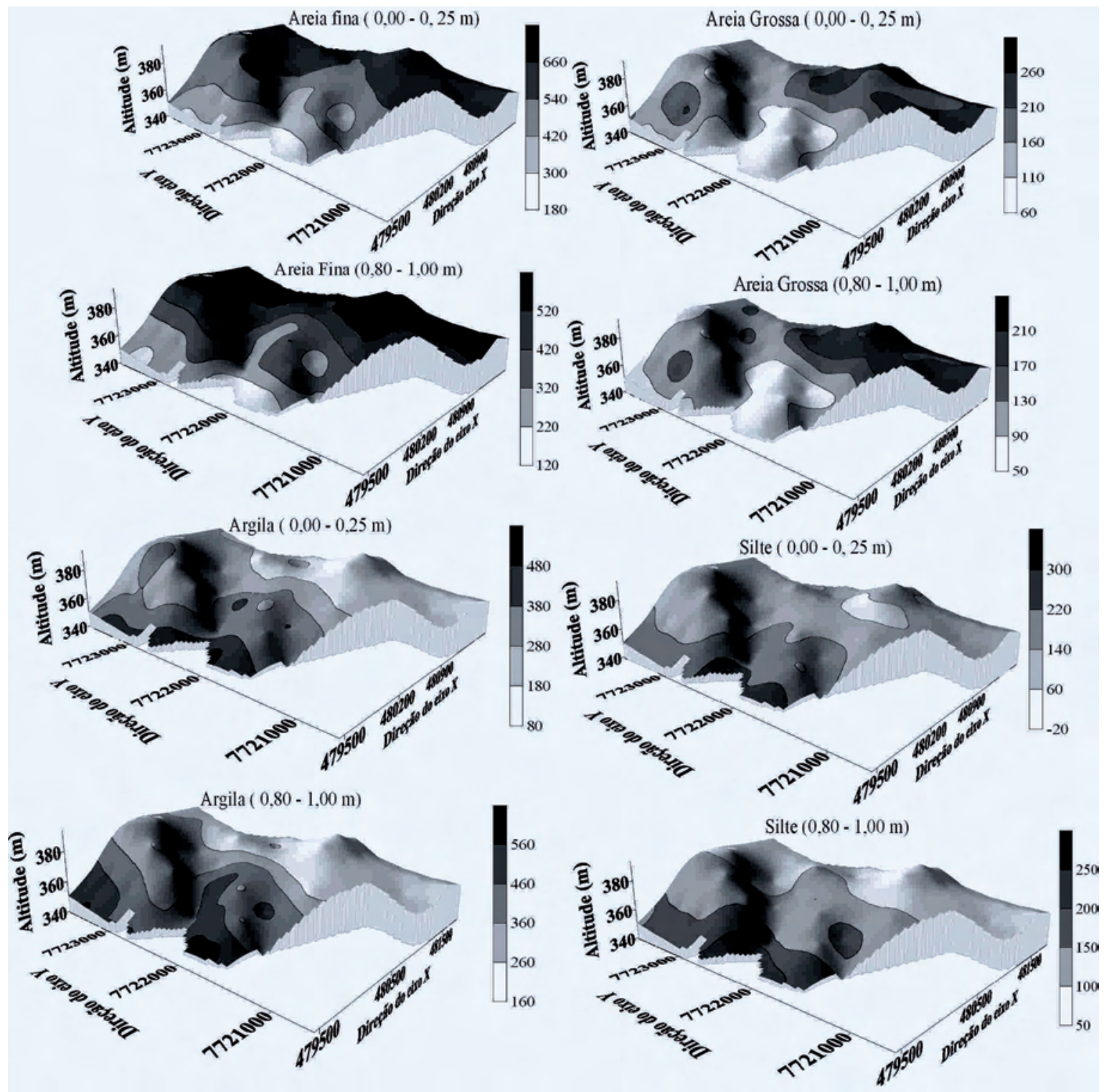

Figura 3. Mapas de krigagem dos teores de areia fina, areia grossa, silte e argila do solo $\left(\mathrm{g} \mathrm{kg}^{-1}\right)$, nas profundidades $0,00-0,25 \mathrm{~m}$ e 0,80-1,00 m (Pereira Barreto, SP, 2006). 
principalmente, à estrutura da paisagem, que é um importante controlador dos processos erosivos do solo, em função da disposição das formas do relevo, que constitui o principal responsável pela variação dos fatores de erosão, pois influencia o movimento da água no terreno (Oost et al. 2000).
Observou-se aumento gradual dos valores de todos os atributos químicos, partindo da superfície geomórfica I para a superfície III (Figura 4). Esta expressão é confirmada por Teramoto et al. (2001), que destacam que a relação entre solos e superfícies geomórficas é representada pela tendência de que,
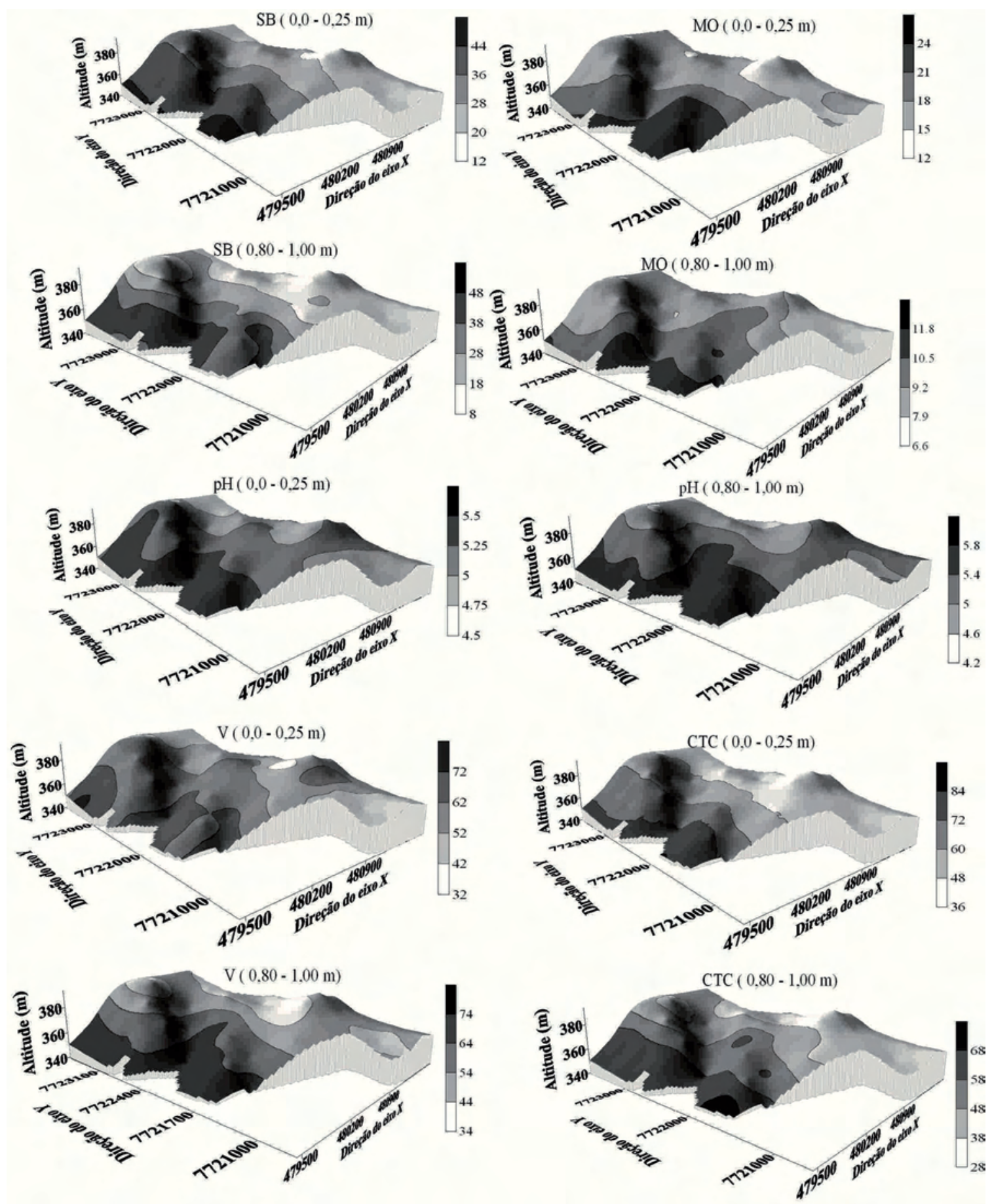

Figura 4. Mapas de krigagem dos teores matéria orgânica (MO), soma de bases (SB), pH, capacidade de troca catiônica (CTC) $\left(\mathrm{mmol}_{\mathrm{c}} \mathrm{dm}^{-3}\right)$ e saturação de bases (V\%), nas profundidades 0,00-0,25 m e 0,80-1,00 m (Pereira Barreto, SP, 2006). 
quanto mais velha e estável é a superfície, mais homogênea ela deve ser, em relação aos solos que nela ocorrem, ou seja, a complexidade e variabilidade de solos é inversamente proporcional à idade da superfície.

Nota-se que, nas áreas de maiores altitudes, na superfície geomórfica I, todas as variáveis químicas expressaram os menores valores e, nas áreas de menores cotas, observa-se comportamento contrário, corroborando os resultados encontrados por Cunha et al. (2005), que, utilizando os conceitos de superfícies geomórficas como indicadores da idade dos solos, afirmam que a superfície mais velha tem solos mais intemperizados e mais pobres, enquanto as superfícies geomórficas mais jovens têm solos menos intemperizados e mais ricos.

Outro aspecto bastante interessante é que os valores da saturação por bases apresentam um gradiente coincidente com as superfícies geomórficas, sendo distrófico, na superfície geomórfica I, e chegando a eutrófico, na superfície geomórfica III (Figuras 1 e 4), concordando com os resultados encontrados por Klamt \& Beatty (1972) e Uberti \& Klamt (1984), que observaram maior grau de desenvolvimento dos solos em posição de topos e dominância de solos distróficos. Por outro lado, em posições de terraços e áreas escarpadas, há predominância de solos mais jovens e eutróficos.

A espacialização das informações dos atributos do solo e do terreno (Figuras 1, 2, 3 e 4) possibilitou a elucidação e constatação das influências das superfícies geomórficas no comportamento do solo. De acordo com Pennock (2003), por meio dos Modelos de Elevação Digital, podem ser observadas as variações topográficas e estas variações proporcionam melhor entendimento do padrão e distribuição dos fluxos de água no terreno, o que permite estabelecer relações entre as formas do terreno e a variabilidade dos atributos do solo.

\section{CONCLUSÕES}

1. A utilização do conceito de superfícies geomórficas e a identificação do material de origem foram eficientes para o entendimento da variação dos atributos do solo.

2. Com o auxílio de técnicas de geoestatística e Modelo de Elevação Digital, observou-se que os atributos do solo apresentaram limites próximos aos das superfícies geomórficas.

\section{AGRADECIMENTOS}

À Coordenação de Aperfeiçoamento de Pessoal de Nível Superior (Capes), pela bolsa concedida, e à Usina Santa Adélia, pelo apoio financeiro na realização da pesquisa.

\section{REFERÊNCIAS}

BERG, M. van den; OLIVEIRA, J. B. Variability of apparently homogeneous soilscapes in São Paulo State, Brazil. II. Quality of soil maps. Revista Brasileira de Ciência do Solo, Viçosa, v. 24, n. 3, p. 393-407, 2000.

BOCKHEIM, J. G. et al. Historical development of key concepts in pedology. Geoderma, Amsterdam, v. 124, n. 1, p. 23-36, 2005.

BUI, E. N. Soil survey as a knowledge system. Geoderma, Amsterdam, v. 120, n. 2, p. 17-26, 2004.

CARVALHO, J. R. P.; SILVEIRA, P. M.; VIEIRA, S. R. Geoestatística na determinação da variabilidade espacial de características químicas do solo sob diferentes preparos. Pesquisa Agropecuária Brasileira, Brasília, DF, v. 37, n. 8, p. 1151-1159, 2002.

CARVALHO, M. P.; TAKEDA, E. Y.; FREDDI, O. S. Variabilidade espacial de atributos de um solo sob videira em Vitória Brasil (SP). Revista Brasileira de Ciência do Solo, Viçosa, v. 27, n. 4, p. 695-703, 2003.

CUNHA, P. et al. Superfícies geomórficas e atributos de latossolos em uma sequência arenítico-basáltica da região de Jaboticabal (SP). Revista Brasileira de Ciência do Solo, Viçosa, v. 29, n. 1, p. 81-90, 2005.

DANIELS, R. B.; GAMBLE, E. F.; CADY, J. G. The relation between geomorphology and soil morphology and genesis. Advances in Agronomy, Madison, v. 23, n. 1, p. 51-87, 1971.

EGUCHI, E. S.; SILVA, E. L.; OLIVEIRA, M. S. de. Variabilidade espacial da condutividade hidráulica do solo saturado e da taxa de infiltração básica determinadas "in situ". Ciência e Agrotecnologia, Lavras, ed. especial, p. 1607-1613, 2003.

EMPRESA BRASILEIRA DE PESQUISA AGROPECUÁRIA (Embrapa). Centro Nacional de Pesquisa de Solos. Manual de métodos de análise de solo. Rio de Janeiro: Embrapa, 1997.

EMPRESA BRASILEIRA DE PESQUISA AGROPECUÁRIA (Embrapa). Centro Nacional de Pesquisa de Solos. Sistema brasileiro de classificação de solos. Brasília, DF: Embrapa, 2006.

GOBIN, A.; CAMPLING, P.; FEYEN J. Soil-landscape modelling to quantify spatial variability of soil texture. Physics and Chemistry of Earth, Oxford, v. 26, n. 1, p. 41-45, 2001. 
GOLDEN SOFTWARE INC. Surfer for windows: realese 7.0 , contouring and 3D surface mapping for scientist's engineers user's guide. New York: Golden Software Inc., 1999.

HAMMER, R. D. et al. Slope class maps from soil survey and digital elevation models. Soil Science Society American Journal, Madison, v. 59, n. 2, p. 509-519, 1995.

INSTITUTO DE PESQUISAS TECNOLÓGICAS (IPT). Mapa geomorfológico do Estado de São Paulo: escala 1:1.000.000. São Paulo: IPT, 1981a.

INSTITUTO DE PESQUISAS TECNOLÓGICAS (IPT). Mapa geológico do Estado de São Paulo: escala 1:500.000. São Paulo: IPT, 1981b.

KLAMT, N.; BEATTY, M. T. Gênese duma sequência de solos da região do Planalto médio Riograndense. Pesquisa Agropecária Brasileira, Brasília, DF, v. 7, n. 5, p. 99-109, 1972.

MARQUES JÚNIOR, J.; LEPSCH, I. F. Depósitos superficiais neocenozóicos, superfícies geomórficas e solos em Monte Alto, SP. Geociências, São Paulo, v. 19, n. 2, p. 90-106, 2000.

McBRATNEY, A. B.; HART, G. A.; McGARRY, D. The use of region partitioning to improve the representation of geostatistically mapped soil attributes. Soil Science, Baltimore, v. 3, n. 3, p. 513-533, 1991.

McBRATNEY, A. B.; SANTOS, M. L. M.; MINASNY, B. On digital soil mapping. Geoderma, Amsterdam, v. 117, n. 2, p. 3-52, 2003.

McBRATNEY, A. B.; WEBSTER, R. Choosing functions for semi-variograms of soil properties and fitting them to sampling estimates. Soil Science, Baltimore, v. 37, n. 2, p. 617-639, 1986.

MELlo, G.; BUENO, C. R. P.; PEREIRA, G. T. Variabilidade espacial das propriedades físicas e químicas do solo em áreas intensamente cultivadas. Revista Brasileira de Engenharia Agrícola e Ambiental, Campina Grande, v. 10, n. 2, p. 294-305, 2006.

OOST, K. V.; GOVERS, G.; DESMET, P. Evaluating the effects of changes in landscape structure on soil erosion by water and tillage. Landscape Ecology, New York, v. 15, n. 6, p. $577-589,2000$.

PARK, S. J.; BURT, T. P. Identification and characterization of pedogeomorphological processes on a hillslope. Soil Science Society American Journal, Madison, v. 66, n. 2, p. 1897-1910, 2002.

PENNOCK, D. J. Terrain attributes, landform segmentation, and soil redistribution. Soil \& Tillage Research, Amsterdam, v. 69, n. 2, p. 15-26, 2003.

RAIJ, B. van; QUAGGIO, J. A.; CANTARELLA, H. Análise química do solo para fins de fertilidade. Campinas: Fundação Cargill, 1987.
ROBERTSON, G. P. GS+ geostatistics for the environmental sciences: GS+ user's guide. Plainwell: Gamma Design Software, 1998.

RUHE, R. V. Geomorphic surfaces and the nature of soils. Soil Science, Baltimore, v. 82, n. 6, p. 441-445, 1956.

SANTOS, R. D. et al. Manual de descrição e coleta de solos no campo. 5. ed. Viçosa: Sociedade Brasileira de Ciência do Solo, 2005.

SCHLOTZHAVER, S. D.; LITTELL, R. C. SAS: system for elementary statistical analysis. 2. ed. Cory: SAS, 1997.

SOUZA, Z. M. et al. Variabilidade espacial da textura de um Latossolo Vermelho eutroférrico sob cultivo de canade-açúcar. Engenharia Agrícola, Jaboticabal, v. 24, n. 2, p. 309-319, 2004.

TERAMOTO, E. R.; LEPSCH, I. F.; VIDAL-TORRADO, P. Relações solo, superfície geomórfica e substrato geológico na microbacia do Ribeirão Marins (Piracicaba - SP). Scientia Agricola, Piracicaba, v. 58, n. 2, p. 361371, 2001.

UBERTI, A. A.; KLAMT, E. Relações solos-superfícies geomórficas na encosta inferior do nordeste do Rio Grande do Sul. Revista Brasileira de Ciência do Solo, Campinas, v. 8, n. 4, p. 229-234, 1984.

VIDAL-TORRADO, P.; LEPSCH, I. F. Relações material de origem/solo e pedogênese em uma sequência de solos predominantemente argilosos e latossólicos sobre psamitos na Depressão Periférica Paulista. Revista Brasileira de Ciência do Solo, Viçosa, v. 23, n. 2, p. 357-369, 1999.

VIEIRA, S. R. Geoestatística em estudo da variabilidade espacial do solo. In: NOVAIS, R. F. de; ALVAREZ V., V. H.; SCHAEFER, C. E. G. R. (Eds.). Tópicos em Ciência do Solo. Campinas: Sociedade Brasileira de Ciência do Solo, 2000. p. 1-54.

WARRICK, A. W.; NIELSEN, D. R. Spatial variability of soil physical properties in the field. In: HILLEL, D. (Ed.). Applications of soil physics. New York: Academic, 1980. p. 319-344.

WILDING, L. P.; DREES, L. R. Spatial variability and pedology. In: WILDING, L. P.; DREES, L. R. (Eds.). Pedogenesis and soil taxonomy: concepts and interactions. New York: Elsevier, 1983. p. 83-116.

YOO, K. et al. Spatial patterns of soil organic carbon on hillslopes: integrating geomorphic processes and the biological C cycle. Geoderma, Amsterdam, v. 130, n. 2, p. 47-65, 2006. 